\title{
La representación iconográfica en mapas antiguos y su descripción catalográfica \\ El caso de las mapotecas de bibliotecas nacionales de lberoamérica
}

\author{
( Nancy Bentivegna \\ Universidad de Buenos Aires, Facultad de Filosofía y Letras, Instituto de Geografía "Romualdo Ardissone" I \\ nbentivegna8o@gmail.com / Orcid: oooo-0oo2-9527-469o
}

\begin{abstract}
Resumen
Con el propósito de examinar los procedimientos implicados en el tratamiento técnico de imágenes iconográficas representadas en mapas antiguos, se realizó una investigación cualitativa que analizó el conjunto de prácticas y lineamientos aplicados en las mapotecas de bibliotecas nacionales iberoamericanas para la catalogación y sistematización de estos elementos. Se efectuó una observación estructurada sobre un porcentaje de registros de alto contenido iconográfico disponibles en los catálogos en línea de las bibliotecas de estudio y se cotejaron los datos relevados con la normativa catalográfica vigente y con el método iconológico de Panofsky, proveniente del ámbito de la teoría e historia del arte. Por último, a través de un cuestionario, se recabó información vinculada al establecimiento de políticas y manuales de procedimientos elaborados por estas instituciones para el abordaje de imágenes en cartografía antigua.
\end{abstract}

The iconographic representation on early maps and their catalographic description: the case of the map libraries of national libraries in Ibero-America

\begin{abstract}
With the purpose of examining the procedures involved in the technical treatment of iconographic images represented on early maps, a qualitative investigation was carried out that analyzed the set of practices and guidelines applied in the map libraries of Ibero-American national libraries for cataloging and systematization of these elements. A structured observation was made on a percentage of records with high iconographic content available in the online catalogs of the study libraries and the data collected was compared with the current cataloging regulations and with the iconological method of Panofsky, from the field of theory and art history. Finally, through a questionnaire, information related to the establishment of policies and procedures manuals prepared by these institutions for the approach of images in old cartography was collected.
\end{abstract}

\section{Palabras clave}

Iconografía Catalogación de mapas antiguos

Catalogación de imágenes Iberoamérica

Método Iconológico de Panofsky

\section{Keywords}

Iconography Cataloging of early maps Image Cataloging Iberoamerica Panofsky's iconological method 


\section{Introducción}

Los fondos cartográficos antiguos pertenecientes a las principales mapotecas de Iberoamérica representan un verdadero tesoro histórico, artístico y cultural, fruto del conocimiento y las exploraciones de los más grandes navegantes y cartógrafos de la Edad Media y el Renacimiento. Estas colecciones se encuentran generalmente a resguardo en sectores diferenciados y presentan características peculiares que requieren de un tratamiento especializado por parte de los catalogadores, especialmente en lo vinculado a la descripción de iconografías insertas en estos recursos. Estos elementos visuales, muchas veces identificados y descriptos en los registros bibliográficos, proporcionan información valiosa desde múltiples perspectivas y requieren de un abordaje técnico preciso y sensible.

Dada esta complejidad, este estudio propone examinar los procedimientos técnicos y metodológicos implicados en la lectura y descripción de visualidades en cartografía antigua, reflejados en los catálogos en línea de las bibliotecas, así como en los manuales y políticas internas institucionales. Para realizar el abordaje propuesto al tema, se seleccionó como población de estudio el conjunto de mapotecas emplazadas en las bibliotecas nacionales de Iberoamérica y se indagó en el trabajo llevado a cabo por los catalogadores en relación al tratamiento técnico de imágenes iconográficas contenidas en mapas producidos entre los siglos XVI-XIX. La información relevada se cotejó con la normativa catalográfica vigente y con el método iconológico de Panofsky, de potencial aplicación en el ámbito de la catalogación de cartografía antigua.

Además, se plantearon hipótesis de trabajo que establecen, en primer lugar, que la descripción de iconografías presentes en mapas antiguos es realizada por los catalogadores a través de un orden discursivo estructurado, no establecido por reglas de catalogación, sino por políticas propias de cada biblioteca. En segundo lugar, que la selección de estos elementos visuales, su ordenamiento sintáctico y nivel de interpretación semántica se plasman en una política o manual de procedimientos técnicos $\mathrm{y}$, en tercer lugar, que su descripción catalográfica se corresponde principalmente con niveles de significación de tipo pre-iconográfico, en contraposición a niveles de interpretación iconográficos e iconológicos de acuerdo con el método de Panofsky.

Por último, se infiere que los catalogadores describen mayormente los elementos visuales contenidos en las cartelas de los mapas, en detrimento de los elementos dispuestos en otras secciones y, además, que las descripciones con tendencias iconográficas e iconológicas son efectuadas a partir del empleo de diversas fuentes externas de apoyo a la catalogación y manuales de interpretación de reglas de catalogación.

\section{El mapa antiguo y su catalogación}

Se entiende por mapa antiguo todo material plano producido entre los años 1500 y 1901 y que, perdida su función inicial, ha pasado a convertirse en una pieza de interés artístico o histórico (Jiménez Pelayo, 1996). Para Crespo Sanz y Fernández Wyttenbach (2011) observar un mapa antiguo requiere de una visión hermenéutica y pone en juego desafíos en relación al conjunto de conocimientos que implican: técnicas de navegación y topografía, procesos de impresión y grabado, paleografía, emblemas y heráldica (Harley y Woodward, 1987). Este conglomerado de conocimientos, también conocido como geo-literacy (Aber y Aber, 2017), es vital para el bibliotecario de mapas ya que, como sostienen los autores, sin alfabetización geográfica los bibliotecarios pierden experiencia y tratan a los mapas como 'el niño problemático de la colección'. Así, se entiende que el mapa antiguo interroga al catalogador y lo lleva a indagar en el 
proceso de producción del mapa y los actores involucrados: el contexto del cartógrafo, el de otros mapas asociados y el entorno social en que fue creado (Harley, 2001).

Existen actualmente cuatro reglas de catalogación en vigencia que aplican al tratamiento descriptivo de los materiales cartográficos: Angloamerican Cataloguing Rules (AACR2, 2002-2005), International Standard Bibliographic Description for Cartographic Materials (ISBD CM, 2004), International Standard Bibliographic Description Consolidated Edition (ISBD Edición consolidada, 2011) y Resource Description and Access (RDA, 2010). Estos repertorios establecen algunas prescripciones en relación al abordaje descriptivo de imágenes en cartografía, principalmente en lo que refiere a la confección de notas de tipo identificativas y cartográficas (Jiménez Pelayo, 1996). Este tipo de información suele registrarse a partir de la consideración de las imágenes como elementos decorativos complementarios y es reseñada en todas las normas de forma genérica, sin proporcionar mayores especificaciones en torno a la cuestión iconográfica.

Ante esta situación, es de utilidad el empleo de manuales de interpretación de reglas, ya que en muchos casos proporcionan estrategias efectivas para la toma de decisiones operativas y procedimentales. En este sentido, la especialista en catalogación de mapas antiguos Nancy Kandoian (1999) recomienda el uso de cuatro repertorios: Cartographic materials: a manual of interpretation for AACR2 (2003); Map cataloguing manual (Library of Congress Geography and Map Division, 1991); Manual for the cataloguing of antiquarian cartographic materials (Karrow, 1997) y Descriptive cataloguing of rare books, conocido como DCRB (1991).

Se añade a las recomendaciones de la autora el manual Descriptive Cataloguing of Rare Materials (Cartographic), publicado en el año 2016 por Rare Books and Manuscripts Section of the Association of College and Research Libraries. Este repertorio -basado en $A A C R 2$ y en los manuales de interpretación Descriptive Cataloging of Rare Materials: a manual of interpretation for $A A C R 2$ y Cartographic Materials: a manual for interpretation for $A A C R 2$ - incluye una detallada sección para el área de notas, principalmente en cuanto al tratamiento de imágenes contenidas en estos recursos.

\section{La iconografía en el mapa antiguo}

Las representaciones cartográficas han sido, a lo largo de la historia, los escenarios en los cuales se recrearon imágenes -empíricas, fantásticas- de los habitantes de las nuevas configuraciones territoriales (el Nuevo Mundo), sus hábitos y costumbres. Estos diseños iconográficos, plasmados en cartelas, márgenes, océanos y continentes del mapa, fueron desarrollados a través de diferentes técnicas de ilustración, grabado y reproducción calcográfica y llevaron -de acuerdo a la época de producción- la impronta del estilo artístico de influencia medieval, renacentista o barroca. Muchas de estas imágenes, llegadas a la cartografía a partir de la influencia y circulación de bestiarios y cosmografías medievales ${ }^{1}$, representaban además las relaciones de dominio predominantes entre conquistadores/conquistados, exploradores/autóctonos y llevaban consigo la huella subjetiva del cartógrafo, cuya mirada reflejaba la red de intereses políticos de su tiempo (Machado Lorenzo, 2009).

En este estudio, se han establecido once categorizaciones representativas de tipos iconográficos, de acuerdo a caracterizaciones específicas presentes en la cartografía antigua. Por un lado, las 'Iconografías mitológicas, razas monstruosas y mirabilia', representadas mayormente por imágenes vinculadas a deidades y personajes míticos del universo griego, romano, católico y pagano como dioses, semidioses, tritones, sirenas, ángeles, monstruos y seres antropomorfos. Por otro lado, 'Personajes humanos', representados por figuras de distintos estratos sociales como cartógrafos, reyes,
1. Algunos ejemplos: Nova iconología de Cesare Ripa (1603) y De Imaginum, signorum et idearum compositione de Giordano Bruno (1591). 
cosmógrafos, príncipes, personas asociadas a la vida política, social y episcopal, así como habitantes y pobladores autóctonos.

Otra categoría está conformada por 'Escenas' como canibalismo, comercio, conquista, batallas y relaciones interculturales, entre otras. Por otra parte 'Elementos varios de uso humano', que adoptan la forma de carabelas, flotas, naves de distinto velamen y calado, canoas, barcos de carga y descarga, dispositivos de medición cartográfica y astronómica, monedas, cofres, armas, sombrillas y vasijas, entre otros. Además, 'Emblemas' como banderas, escudos de armas de las personas o familias a quienes estaban dedicados los mapas o de las naciones y/o ciudades representadas, coronas, etc.

En relación a las representaciones del mundo natural, se encuentran las categorías de 'Vientos, fenómenos climáticos, astronómicos, elementos yestaciones', es decir, soplones, elementos de la naturaleza (aire, tierra, fuego, aire), eclipses, planetas, signos zodiacales y constelaciones y 'Representaciones de puntos cardinales' rosas de los vientos y flores de lis como los diseños más utilizados. En vinculación al mundo animal y vegetal, se encuentran 'Fauna' de la región representada -real, imaginaria, o propia del territorio del explorador o cartógrafo- y 'Flora' recreada con imágenes de cultivos, vegetación y frutos. Estos últimos se ilustraban para representar lo exótico del territorio o simbolizar dominio, a partir de la inserción de, por ejemplo, frutos europeos en otras geografías.

Por último, se incluyen 'Sitios y maravillas del mundo antiguo' como los Jardines colgantes de Babilonia, el Templo de Artemisa y la Estatua de Zeus; 'Retratos' de navegantes, exploradores, cartógrafos, y diferentes personalidades de importancia para la vida política, social o cultural y 'Elementos puramente decorativos' como orlas, guirnaldas y diversos diseños arquitectónicos que se empleaban principalmente como ornamento de cartelas y estampas.

\section{Método iconológico de Panofsky}

Para la interpretación de obras visuales e iconografía el historiador del arte Erwin Panofsky (1892-1968) ha desarrollado una metodología de amplio alcance y aplicación en la investigación social e histórica. Se trata de un método esquemático que, con la finalidad de proporcionar un estudio del contexto histórico en el que fue concebido un bien cultural o artístico, recurre a la identificación de símbolos, sus representaciones alegóricas y sus atributos, articulado en tres niveles de interpretación que se consideran inseparables del acto interpretativo de las obras visuales (Richter Scheuch y Valdivieso García, 2008).

El primer nivel establecido es el pre-iconográfico, vinculado al reconocimiento de la obra en su sentido fáctico o expresivo, basado en la experiencia práctica y natural de aquello que se observa. Consiste en identificar las formas puras, los objetos (árboles, personas, edificios) y situaciones (batallas, banquetes). Requiere el conocimiento básico de estilos artísticos y la reacción sensible del observador frente al objeto que contempla.

El segundo nivel es el conocido como iconográfico, que aborda el análisis del significado o los temas y conceptos expresados (connotación) en el objeto. Implica el manejo de fuentes bibliográficas y un mayor conocimiento de los códigos artísticos y/o culturales, emblemas y alegorías. Es inteligible, es decir, requiere de saberes preestablecidos, sin intervención de los sentidos humanos. 


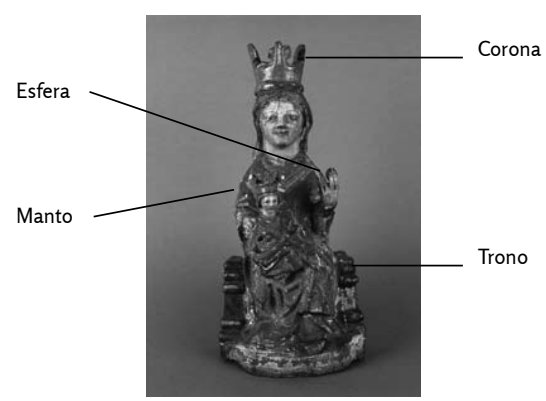

Nivel 1: (Pre-iconográfico): Objeto exento, tridimensional de figura femenina de expresión hierática sentada sobre un trono con un niño sobre las rodillas, ambos llevan coronas sobre las cabezas y una esfera en sus manos; la figura femenina viste un manto de color rojo y azul.

Nivel 2:(Iconográfico): Esta imagen está relacionada con un dogma religioso: Es una theotokos (Virgen Madre, también denominada "la que engendra al Niño Dios") o Virgen entronizada como "Madre de Dios" o "Reina de los Cielos" y las coronas sobre sus cabezas demuestran una jerarquía espiritual.

La Virgen está sentada en un trono debido a su dignidad, los colores de su ropaje también corresponden a ese atributo. Representa además a una madre, la del hijo de Dios, es decir, a la Virgen María, ambos mirando al frente. El niño que lleva en sus brazos es Jesús, quien apoya en su mano izquierda un orbe como signo de soberanía.

Es una imagen de devoción que representa una maternidad virginal, la gloria de la Madre con su hijo, con sus dolores y alegrías. Considerando sus dimensiones, se usaba para su adoración en altares pequeños.

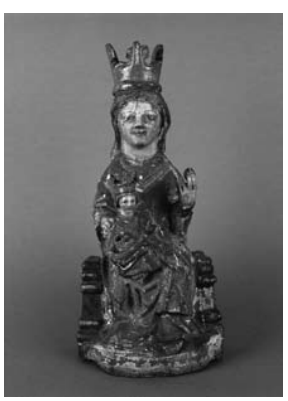

Imagen: Propiedad del Museo de Artes Decorativas, Santiago, Chile.

Nivel 3: (Interpretación iconológica): Esta pieza escultórica no se encuentra fechada, sin embargo se conoce que su procedencia es europea.

El hecho que tanto la Virgen como el Niño Dios porten en sus manos un orbe, permite identificar esta escultura dentro de la imaginería románica, (“Iconografía del arte colonial, Los Santos. Vol. II”, Héctor H. Schenone, Ed. Fundación Tarea, Buenos Aires, 1992. p. 821), ya que en la Alta Edad Media se destaca la representación a la Virgen según esta forma, theotokos, dentro del mundo cristiano de Oriente bizantino.

La religiosidad popular de la Edad Media surgió a partir del desarrollo teológico por parte de la Iglesia y el uso del color dorado como el oro, les permitían a estas figuras actuar como agentes de iluminación espiritual.

El tercer nivel es el iconológico, que se corresponde con la búsqueda del contenido y el valor intrínseco, condicionado por la subjetividad del intérprete. Indaga en el significado inconsciente de la obra, los valores simbólicos que permiten su entendimiento como documento histórico y que reflejan el pensamiento e idiosincrasia de un hecho o período determinado. Es intuitivo y sintético, interpreta en contexto los temas y conceptos identificados en los niveles anteriores. En relación a lo expuesto, es de interés la aplicación de esta metodología propuesta por Marisol Richter Scheuch y Cynthia Valdivieso García (2008), quienes realizan una ejemplificación sobre un objeto escultórico a partir de la esquematización de acuerdo a niveles de interpretación (Figura 1).

Así, en un nivel pre-iconográfico se describen aquellas características percibidas a través del conocimiento sensible o fáctico como formas, colores y objetos asociados a la pieza; en un nivel iconográfico se asocian dogmas y simbologías propias del conocimiento teológico inherente a la pieza analizada y, por último, en un nivel iconológico se identifica la procedencia del objeto, su pertenencia a una corriente artística y se referencia a una fuente externa para, finalmente, vincular la obra y su significado con el contexto histórico de la época.

A partir de la consideración del mapa como objeto artístico, documento histórico y producto cultural (Montoya Arango, 2007) y del vacío existente en las reglas de catalogación en la vinculación al tratamiento descriptivo de imágenes, es que se observa que este método puede trasladarse a la catalogación de mapas, principalmente para proporcionar herramientas metodológicas necesarias para el abordaje técnico de estos recursos. De este modo, un nivel pre-iconográfico en el análisis de un mapa será una descripción general y superficial de los elementos identificados: una mujer, una corona, un escudo, una batalla; un nivel iconográfico será un acercamiento al
Figura 1. Modelo de ejercicio fragmentado según niveles(Richter Scheuch y Valdivieso García, 2008: 98) 
contenido del mapa como obra y la decodificación de representaciones alegóricas y simbólicas: la mujer es una alegoría del continente americano, la corona pertenece al Reino de Sevilla, el escudo representa el Reino de España y la escena recrea una batalla histórica. Finalmente, un nivel iconológico será una descripción del contexto en que fue elaborado el mapa, las motivaciones del artista/cartógrafo para desarrollarlo y los elementos que llevan a que el objeto cartográfico sea considerado de algún valor como documento histórico, representativo de un período específico.

\section{Procedimiento}

Se llevó a cabo una investigación cualitativa, con un diseño estructurado y transversal, que permitió obtener datos en un período de tiempo acotado y pautado previamente. Se determinó realizar el análisis sobre las mapotecas iberoamericanas que poseen los fondos cartográficos más antiguos y los registros bibliográficos más detallados, es decir, aquellas que se encuentran emplazadas en las bibliotecas nacionales. Para obtener la información necesaria se utilizó una estrategia mixta, que consistió en la confección y aplicación de dos herramientas de ingesta que permitieron triangular y complementar datos: una grilla de observación y un cuestionario mediante un formulario de Google Forms.

En la etapa de la observación, primero se efectuó una pre-navegación por los catálogos en línea de las bibliotecas/mapotecas, con la intención de identificar aquellos que efectivamente contienen material cartográfico antiguo descripto en sus registros bibliográficos. Luego, se realizó una búsqueda avanzada combinada por tipo de mate$\mathrm{rial} /$ formato y términos de indización específicos como 'mapas antiguos' o 'cartografía antigua'. Como material de apoyo, se confeccionó un listado de cartógrafos reconocidos del período de estudio a fin de contar con un registro de autoría fehaciente que permita identificar más fácilmente los recursos seleccionados para el análisis.

Sobre los resultados arrojados en las búsquedas se realizó una meta-observación, que consistió en analizar individualmente cada uno de los registros recuperados para así seleccionar los más representativos. En los casos en que se superó el promedio establecido de los 500 registros se seleccionó el 10\% del total. Los datos fueron transcriptos en listados confeccionados por biblioteca/mapoteca, en secuencias ordenadas de acuerdo a la presentación de datos de cada catálogo.

Para el registro de la información producto de la observación, se reseñaron en una bitácora aquellos elementos distintivos y sus peculiaridades identificadas y se transcribieron en la grilla los contenidos textuales de cada uno de los registros analizados y su codificación MARC21. Esta herramienta se estructuró en 4 unidades de análisis basadas en lineamientos específicos prescriptivos, sintácticos y semánticos, sustentados en normas y estándares bibliotecológicos y en el método iconológico de Panofsky (1939).

En primer lugar, se definió la unidad 'Información general' en donde se consignaron aquellos datos necesarios para la identificación de cada uno de los registros/ mapas observados: título, autor, cronología, enlace web y biblioteca depositaria. En segundo lugar, se estableció la unidad 'Sistematización', en la cual se registró información relativa a tipos de normas catalográficas empleadas y la codificación MARC21 correspondiente. En tercer lugar, se designó la unidad 'Sintaxis', en donde se establecieron dos segmentos de análisis: 'Tipos de elementos iconográficos descriptos', para la identificación de unidades léxicas equivalentes a las once categorizaciones iconográficas enunciadas anteriormente y 'Ordenamiento, estilo y citas externas' en el cual se identificaron aquellas secuencias textuales vinculadas a la disposición de los 
elementos visuales transcriptos en los registros, el estilo de redacción y la referencia a fuentes de consulta externas.

Por último, se abordaron en 'Semántica' aquellas tendencias detectadas en los registros en función de niveles de interpretación pre-iconográficos, iconográficos e iconológicos, definidos de acuerdo al método iconológico de Panofsky. Para esto, se establecieron parámetros de aplicación que permitieron clasificar las descripciones dentro de estas categorías. Se determinó como primer parámetro que los registros con tendencias pre-iconográficas serían aquellos en los que se identificaran objetos, formas y situaciones genéricas como eventos aislados, sin denominación específica. Además, se pautó que en los casos en que se proporcionara alguna información de tipo contextual y/o interpretativa más profunda o se indicara la referencia a una o más fuentes externas utilizadas, la descripción sería de tipo pre-iconográfica avanzada.

El segundo parámetro permitió establecer qué descripciones se corresponden con niveles de tipo iconográficos en función de, por un lado, la decodificación de imágenes específicas, alegorías, símbolos y escenas y, por otro, la identificación de referencias a fuentes externas por medio de citas bibliográficas. Además, en los casos en que se observó que la información proporcionada se encontraba cercana al plano iconológico, se determinó que la descripción se ubicaría dentro de un nivel de significación iconográfica avanzada. Por último, se pautó que los registros de tendencia iconológica serían aquellos en los cuales se identificarían e interpretarían contextos de producción y/o información vinculante al recurso, significados de contenido y/o información asociada al mismo, pertenencia a escuelas cartográficas y/o artísticas, valores simbólicos e intencionalidad del mapa, del cartógrafo y/o del ilustrador. Dada la naturaleza de los datos recabados, los bloques de elementos relativos a tipologías iconográficas y niveles de significación se representaron, además, cuantitativamente.

Para la etapa de la encuesta, se logró contactar por correo electrónico a 8 responsables de mapotecas de un total de 22 bibliotecas, a los cuales se envió un enlace al cuestionario. La herramienta se estructuró en base a preguntas cerradas y abiertas, con el fin de obtener información complementaria a la observación y que permita identificar cuestiones de la esfera procedimental: políticas catalográficas aplicadas y manuales de procedimientos internos que reflejen el accionar y tratamiento dado al trabajo descriptivo con imágenes presentes en cartografía antigua. Dado al alcance y distribución, se confeccionó en dos idiomas, español y portugués.

\section{Análisis de resultados}

\section{Resultados por Biblioteca}

En la Biblioteca Nacional Mariano Moreno (Argentina), las reglas de catalogación empleadas son AACR2 y el formato de datos utilizado es MARC21. La codificación para la descripción de iconografías se realiza en campos 500 de notas generales, con un rango de repetitividad de 3 a 5 veces por registro, de acuerdo al tipo de dato representado: iconografías específicas (rosas de los vientos en la mayor parte de los casos); información visual proveniente de cartelas; información asociada a la producción del mapa; particularidades de las representaciones territoriales; otras informaciones como notas explicativas y/o dedicatorias; y por último, secuencias textuales que se suelen incluir en estos recursos.

En el plano sintáctico, el elemento iconográfico mayormente representado es 'Figuras humanas', principalmente en relación a las imágenes insertas en cartelas. Se advierte que las ilustraciones descriptas son consignadas a partir del uso de abundantes 
adjetivaciones y de la reseña de ubicaciones muy específicas. Las notas se efectúan en un único párrafo, en secuencias narrativas de mediana extensión. En relación al registro estilístico, se observa el empleo de algunos diminutivos (piecitos, caritas), situación que da cuenta de un estilo narrativo informal. A su vez, se detecta el uso de frases adverbiales y expresiones verbales en modo potencial, que revelan inferencias subjetivas realizadas por el catalogador.

Por otra parte, se advierte una ausencia de citación de fuentes de apoyo a la catalogación. Esta situación no refiere a la falta de empleo de obras de consulta externas, sino a la ausencia de identificación de esta información en el registro que -es válido aclarar- es de carácter opcional. A nivel semántico, la tendencia de descripción es de tipo pre-iconográfica, es decir, se identifican principalmente formas puras, a través del entendimiento práctico y sensible. En los casos en que se detectaron descripciones de tipo iconográficas, se observó la interpretación de escudos y alegorías a partir de la expresión "representaciones de [...]" y la indicación de escenas específicas que demuestran el manejo de códigos culturales y fuentes complementarias. En los registros cuyas descripciones se corresponden con niveles iconológicos, se revela el análisis al contenido de la obra, al propósito con el que fue concebida y su contexto de producción.

Por su parte, en la Biblioteca Nacional de Chile,las reglas de catalogación empleadas son AACR2 y el formato de datos utilizado es MARC21. La codificación para la descripción de iconografías se realiza en campos 500 de notas generales y 505 de notas de contenido, sin repetición por tipo de dato. Cabe destacar la ausencia de un parámetro específico en relación a la selección entre un campo u otro por parte de los catalogadores, detectándose mayor representación del elemento ‘Objetos de uso humano'.

Por otro lado, los casos analizados carecen de información acerca de la ubicación de las iconografías presentes en los recursos.Además, se observa que las notas se efectúan en un único párrafo, en secuencias narrativas breves, con escasas adjetivaciones, sin referenciación a fuentes externas.En relación a las tendencias de representación, predomina el tipo pre-iconográfico. En el caso en que se identificó una descripción iconográfica, se advierte que se decodificó una alegoría.

En la Biblioteca Nacional de Cuba José Martí, las reglas de catalogación empleadas son ISBD (CM) y el formato de datos utilizado es MARC21. La codificación para la descripción de iconografías se realiza en campos 500 de notas generales, con frecuencia de repetitividad en un rango de 2 a 3 veces, en función del grupo visual identificado. Los elementos iconográficos mayormente representados son tres: 'Objetos de uso humano, 'Mitología, seres fantásticos y mirabilia' y ‘Escenas'.

En relación a la ubicación de las imágenes, estas se encuentran en márgenes, títulos, extremos, grabados (estampas) y orlas. En el plano sintáctico, las notas se efectúan en un único párrafo, en secuencias narrativas breves, con escasas adjetivaciones y sin registro de citación a fuentes externas. En el análisis semántico, se determinaron tendencias de significación pre-iconográficas e iconográficas por igual, en varios niveles de profundidad, especialmente en mapas referidos a Cuba.

En el caso de la Biblioteca Nacional de Venezuela, las reglas de catalogación empleadas son AACR2 y el formato de datos utilizado es MARC21. La codificación para la descripción de imágenes se realiza en campos 500 de notas generales y 520 de nota de resumen. De acuerdo a la cuantificación de elementos, el tipo visual mayormente representado es 'Figuras humanas'. 
La ubicación de las imágenes identificadas proviene principalmente de estampas y viñetas situadas en muchos casos sobre la cartela o en sus márgenes. Las notas se efectúan en un único párrafo, en secuencias narrativas breves, con algunas adjetivaciones, principalmente en relación a viñetas, estampas y escenas descriptas. Además, se advierte el empleo de la expresión "que representa" para aludir a interpretaciones específicas.

En relación al uso y citación de fuentes externas, se observa el empleo de repertorios bibliográficos y catálogos, consignados en campos 500 y que se utilizan principalmente para indicar la fuente a partir de la cual se llegaron a datos útiles para la identificación de autores. A nivel semántico, se percibe mayor cantidad de registros de tendencia pre-iconográfica. Las descripciones que se corresponden con niveles iconográficos consignan información relativa a alegorías, personajes y escenas de carácter simbólico.

Por su parte, en la Biblioteca Nacional de España, se utiliza para la catalogación la norma ISBD Edición consolidada y el formato de datos empleado es MARC21. La codificación para la descripción de iconografía se realiza en campos locales 592 para notas de datos específicos y 599 para notas sobre la ilustración. Se observa que el campo 592 se emplea para registrar información sobre rosas de los vientos mientras que el 599 refiere al resto de las imágenes. En la mayor parte de los casos en que se repite este último campo, se hace para discriminar entre distintos elementos o bloques visuales, como por ejemplo embarcaciones y animales fantásticos y, además, para diferenciar la información contenida en diferentes secciones del mapa.

En relación al plano sintáctico, el elemento iconográfico mayormente representado es 'Objetos de uso humano'. En cuanto a la ubicación de las imágenes identificadas en la descripción, estas se encuentran principalmente en las cartelas del mapa. Las notas se efectúan en un único párrafo, en secuencias narrativas breves, con algunas adjetivaciones y expresiones específicasque no se han observado en otros catálogos analizados, como 'cartela arquitectónica', 'escala en filacteria' y 'clave alfabética'. Para el registro de fuentes externas se han empleado los campos 593 de nota al encabezamiento y 596 de nota sobre el área de publicación, para efectuar referencias a repertorios como atlas, catálogos en línea y diccionarios. En todos los casos, se utilizaron para la identificación de autores y/o de obras mayores.

En relación a aspectos del plano semántico, si bien se observa una marcada tendencia pre-iconográfica, se destaca que muchas de las descripciones se ubican dentro de niveles de significación iconográficos. En estos casos, los tipos de elementos que se representan con mayor detalle son 'Mitología, seres fantásticos, mirabilia', 'Emblemas' y 'Escenas', estas últimas, de variada naturaleza.

En la Biblioteca Nacional de Brasil, para la catalogación utilizan AACR2r y el formato de datos empleado es MARC21. La codificación para la descripción se realiza en campos 500 de notas generales, con un rango de repetitividad de 2 a 5 veces; 510 para consignar citas o referencias bibliográficas, una nota por fuente citada; 520 para nota de resumen, principalmente para consignar iconografías e información contextual; y 555 para índices acumulativos u otros instrumentos bibliográficos utilizados. Se advierte que se repite el campo 500 por cada tipo de elemento iconográfico reseñado y que la información de tendencia iconológica se codifica en campos 520.

Los tipos iconográficos mayormente representados son tres: 'Representación de puntos cardinales y vientos' como rosas de los vientos, flor de lis, soplones; 'Mitología, seres fantásticos y mirabilia', por ejemplo, monstruos marinos y gigantes de 


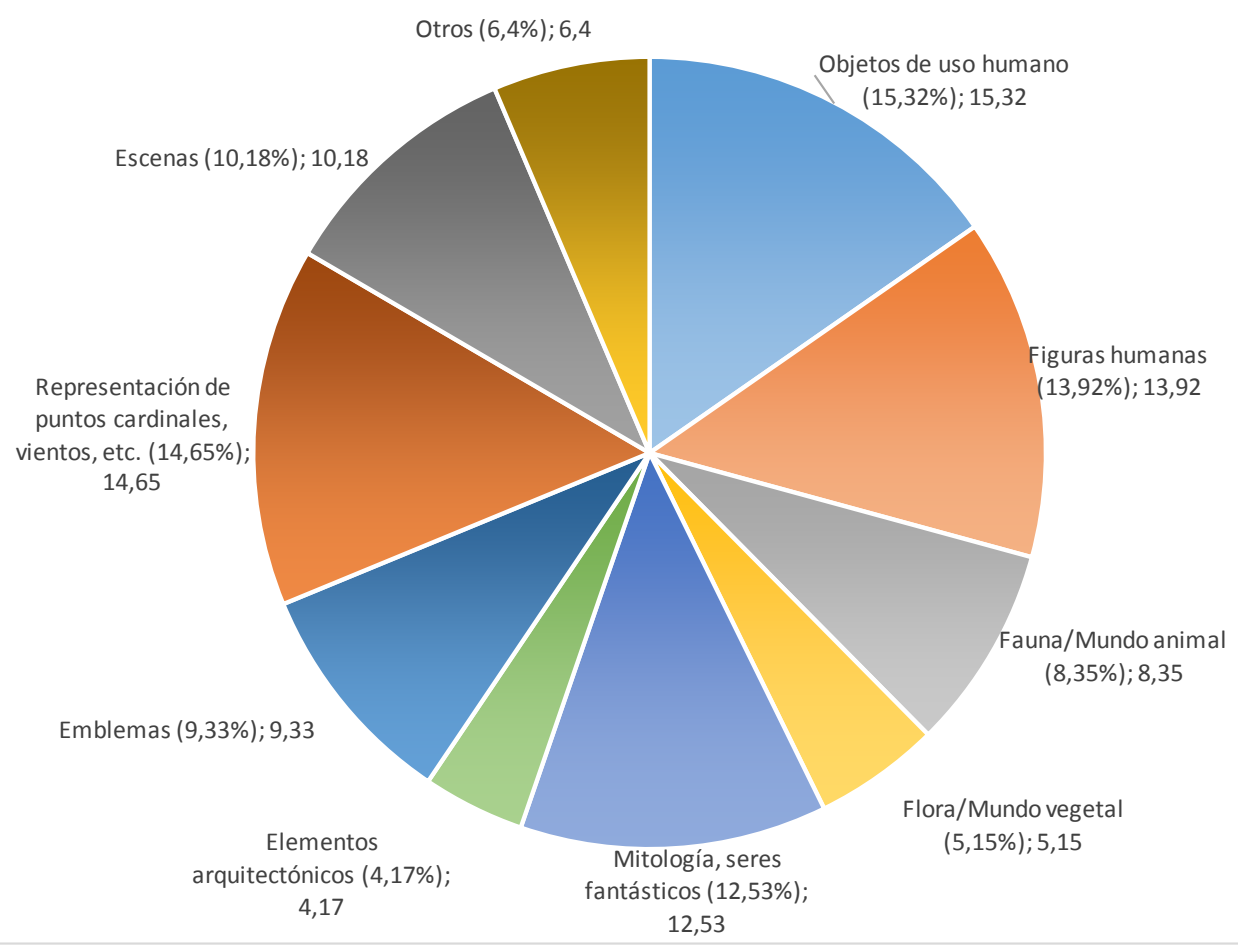

Gráfico 1. Elementos iconográficos representados en registros

la Patagonia; y por último 'Fauna/mundo animal' como figuras marinas, animales silvestres, fauna de América del Sur y pájaros, ubicados principalmente en las cartelas. Las notas se efectúan en un único párrafo, en secuencias narrativas diversas, con algunas adjetivaciones.

Por otra parte, se observa la utilización de terminología y expresiones específicas: se denomina cartuchos a las cartelas (de títulos, de escala, etc.) y se identifican como cartelas a ciertas estampas que se encuentran "encarteladas" y que representan vistas o imágenes arquitectónicas o geográficas específicas. En el registro de uso de fuentes de apoyo se advierte un alto nivel de citación de fuentes históricas especializadas, atlas, catálogos impresos y en línea, repertorios bibliográficos, diccionarios especializados, sitios web y artículos. En la dimensión interpretativa, se detecta una tendencia iconográfica marcada, con presencia de casos de descripciones de tipo iconológicas. Los registros que se corresponden con niveles iconográficos incluyen en su mayor parte citas a fuentes complementarias e interpretan escenas diversas. En aquellos identificados como iconológicos, se incluye información acerca de contextos de producción, pertenencia a escuelas artísticas, intencionalidad y significado e importancia del mapa como documento de valor histórico/documental.

\section{Resultados totales para Iberoamérica}

Se cuantificaron los datos relativos a las iconografías representadas en un total de 223 registros relevados, cuyo valor alcanzó los 718 elementos totales. De acuerdo a los valores establecidos por tipo de elemento, se identificaron porcentajes para cada grupo (Gráfico 1). Así, la unidad visual mayormente consignada para Iberoamérica ha sido 'Objetos de uso humano', con una tasa de uso del 15,32\%. 


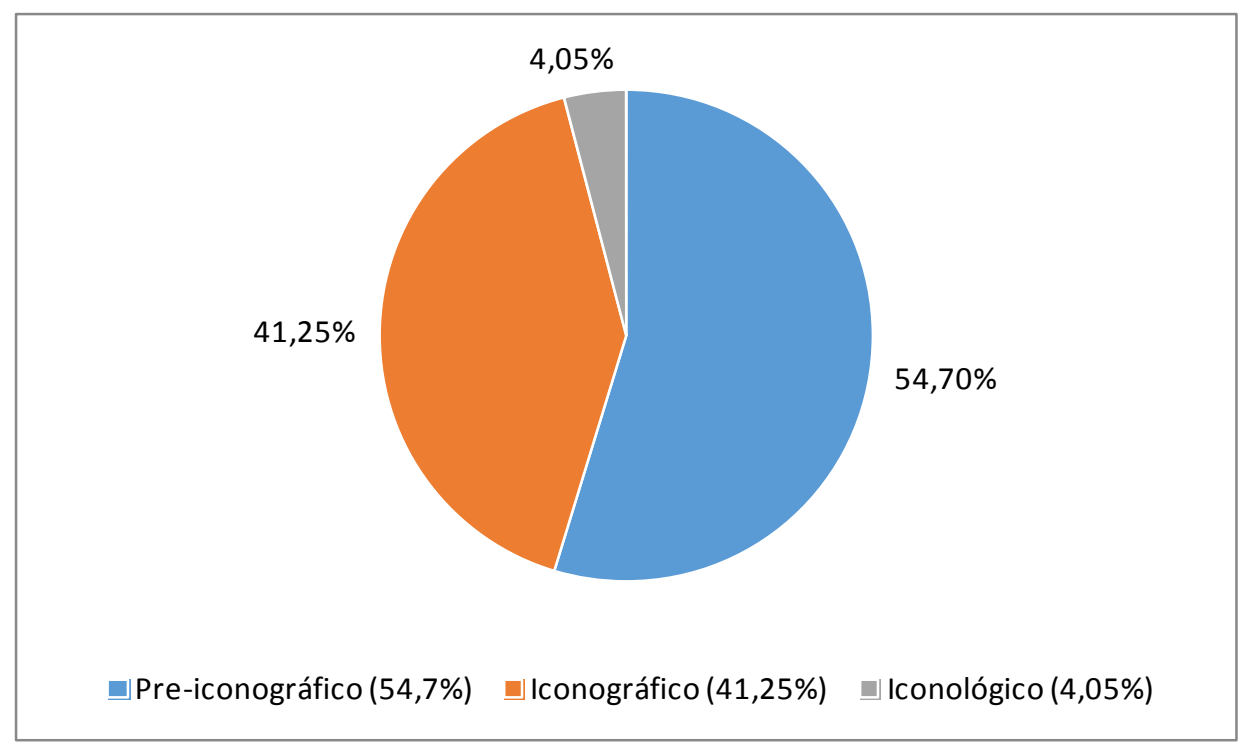

Gráfico 2. Niveles de significación de acuerdo al método iconológico de Panofsky

Además, se cotejaron los datos relativos a niveles de significación de acuerdo al método iconológico de Panofsky, en función de la observación y el análisis efectuado en las descripciones en el área de notas. De acuerdo a los valores establecidos para cada una de las bibliotecas, se identificaron como pre-iconográficos el 54,7\% de los registros, como iconográficos el 41,25\% y como iconológicos sólo un 4,05\%

\section{Resultados de la encuesta}

En esta etapa se analizaron los procedimientos técnicos internos aplicados por las bibliotecas/mapotecas de estudio para la descripción de iconografías. En primer lugar, se indagó acerca del establecimiento de pautas específicas para la identificación de estos elementos en los recursos, y la mitad de los sujetos encuestados manifestaronque por el momento no se han elaborado (50\%). El resto sostuvo que sí las han desarrollado, pero se encuentran en situaciones diferentes: algunas instituciones las han formalizado en un manual de procedimientos (25\%) mientras que otros no hay llegado aún a esa etapa (25\%).

En segundo lugar, se consultó acerca del desarrollo de lineamientos específicos para abordar ladimensión interpretativa y la decodificación de iconografías. En este punto, la mitad de los sujetos (50\%) indicó que aún no han elaborado especificaciones. Un $37,5 \%$ de los sujetos afirmó que han realizado este tipo de procedimientos, pero aún no los han formalizado. El 12,5\% contestó que en la actualidad setrabaja en sudesarrollo, situación que pone de manifiesto la necesidad de su sistematización.En tercer lugar, se abordó la existencia de pautas para el ordenamiento sintáctico y presentación de este tipo de información en los registros, y la mayor parte de los encuestados reveló que las han establecido: el $26 \%$ las ha formalizado en el manual de procedimientos y 
el $37 \%$ las aplica como política interna. Otro $37 \%$ indicó que aún no se han elaborado pautas para esta tarea, sin proporcionar mayores detalles al respecto.

En cuarto lugar, se indagó acerca del valor de identificar, interpretar y dar acceso a estos elementos visuales en los registros y la mayor parte de la población encuestada sostuvo que es de importancia para su comunidad de usuarios (75\%), mientras que el resto expresó que no (12,5\%) y otros, que tal vez sí lo sea (12,5\%). Además, algunos de los sujetos indicaron que en la actualidad se han acrecentado las consultas que reciben en sus bibliotecas sobre iconografías, situación que pone de manifiesto la importancia de ofrecer acceso y estandarizar los procesos vinculados con su tratamiento.

Por último, se consultó acerca del abordaje a imágenes proporcionado por RDA y las respuestas se encontraron divididas: el $25 \%$ indicó que brinda pautas más útiles y específicas en comparación con otras reglas de catalogación, mientras que otro $25 \%$ de los encuestados manifestó que no considera que este repertorio ofrezca mayores posibilidades para la catalogación de información visual representada en este tipo de recursos. El 50\% restante se expresó de forma dubitativa: un $25 \%$ indicó que las nuevas normas tal vez proporcionen beneficios para el abordaje de elementos visuales, mientras que la misma proporción de sujetos (25\%) seleccionó la opción 'otros', sin ofrecer una postura al respecto.

\section{Conclusiones}

En función de la bibliografía consultada y de los resultados expuestos, se observa que la descripción de iconografías es todavía un área en desarrollo, tanto en cuestiones normativas como operacionales del quehacer bibliotecario. Esto se debe principalmente a la ausencia de lineamientos específicos para el tratamiento de elementos visuales en los repertorios catalográficos vigentes, sumado al desconocimiento en el área bibliotecológica de métodos de lectura de imágenes provenientes de la teoría del arte, empleados para la descripción de objetos culturales, artísticos y patrimoniales, potencialmente trasladables al campo de la catalogación de cartografía. Esta situación no sólo lleva a confusiones metodológicas, sino que también dificulta los procesos de estandarización y conversión certera del discurso visual al textual.

En relación a la interpretación y análisis de ilustraciones insertas en mapas, se detecta una tendencia por parte del catalogador a su identificación como entidades aisladas - principalmente aquellas ubicadas en cartelas- así como una marcada propensión a la estructuración de estos elementos en secuencias lógicas y ordenadas por tipo de representación o ubicación en el soporte. En este sentido, se destaca el trabajo realizado en la Biblioteca Nacional de Brasil, en la cual se advierte que la catalogación de estos recursos trasciende lo puramente normativo y la imagen y su contexto cobran un importante protagonismo.

Por otra parte, en cuanto al establecimiento de políticas internas, se observa que, ante la ausencia de especificaciones normativas para el tratamiento de imágenes en recursos cartográficos, algunas de las instituciones relevadas han desarrollado sus propios lineamientos en base a la praxis cotidiana, las necesidades de acceso de los usuarios y al empleo de manuales de interpretación de reglas de catalogación. Cabe destacar que, en algunos casos, estas pautas se han registrado en manuales de procedimientos formales pendientes de publicación. En este sentido, es de suma importancia que las principales mapotecas de la región den a conocer sus prácticas, ante la falta de prescripciones a nivel internacional y el difícil escenario que representa la cartografía en general y la iconografía en particular. 
Se advierte que, dada la complejidad relacionada a la multiplicidad de conceptos e ideas que puede sugerir una imagen, es importante repensar el abordaje en la catalogación a partir del análisis de las instrucciones normativas de las reglas de uso actual -AACR2r, ISBD (CM), ISBD Edición Consolidada y RDA- y de la compresión acerca de la necesidad de complementar dichas normas con otros recursos y fuentes de apoyo. Resulta vital entonces que la praxis de la sistematización y la estandarización de los procesos inherentes a la catalogación se trasladen también a la descripción de iconografías presentes en materiales antiguos y se traduzcan en políticas escritas, en manuales de procedimientos de acceso abierto y en el fortalecimiento de redes de trabajo especializadas y mancomunadas, tendientes a asegurar una catalogación más consciente, plural y, si se quiere, holística.

\section{Agradecimiento}

Deseo expresar mi agradecimiento a la Profesora Nancy Blanco, quien me ha orientado y acompañado en el proceso de investigación del trabajo de campo de graduación que ha sido fundamentación de este artículo. 


\section{Q Referencias bibliográficas}

"Aber, Susan Elizabeth Ward y Jeremy Ward Aber. 2017. Map librarianship: a guide to geoliteracy, maps and GIS resources and services. Cambridge: Chandos Publishing.

"American Library Association. Canadian Library Association. Chatered Institute of Library and Information Professionals and Joint Steering Comitee for Development of RDA. 2010. RDA: Resource Description and Access. Chicago: American Library Association.

"Anglo-American Cataloguing Rules (2nd ed., 2002 revision, 2003, 2005 update). 2002-2005. Ottawa: Canadian Library Association: Chartered Institute of Library and Information Professionals; Chicago: American Library Association.

"Association of College and Research Libraries. Rare books and Manuscripts Section. 2016. DCRM(C): Descriptive Cataloguing of Rare Materials (Cartographic). Chicago: Rare Books and Manuscripts Section, Association of College and Research Libraries. <http://rbms.info/dcrm/dcrmc/> [Consulta: 23 noviembre 2020].

"Cartographic materials: A manual of interpretation for AACR2, 2002 revision (2nd ed.). 2003. Chicago: American Library Association; Ottawa: Canadian Library Association; London: Chartered Institute of Library and Information Professionals.

"Crespo Sanz, Antonio y Alberto Fernández Wyttenbach. 2011. ¿Cartografía antigua o cartografía histórica? En Estudios geográficos. Vol. 72, no. 271, 403-420. $<$ http://estudiosgeograficos.revistas.csic.es/index.php/estudiosgeograficos/ article/view/347> [Consulta: 10 septiembre 2020].

»Descriptive cataloguing of rare books. (2nd. ed.). 1991. Washington, DC: Cataloguing Distribution Service, Library of Congress.

» Harley, John Brian y David Woodward. 1987. History of cartography. Vol. 1: Cartography in prehistoric, ancient and medieval europe and the mediterranean. Chicago: The University of Chicago Press.

" Harley, John Brian. 2001. The new nature of maps: essays in the history of cartography. Baltimore: Johns Hopkins University Press.

»International Federation of Library Associations and Institutions. ISBD Review Group. 2011. ISBD: Consolidated Edition. Berlin: De Gruyter Saur.

» International Federation of Library Associations and Institutions. 2004. ISBD (CM): International Standard Bibliographic Description for cartographic materials (200x revision). <https://archive.ifla.org/VII/s13/pubs/ISBD(CM)_21Deco4. pdf> [Consulta: 23 noviembre 2020].

» Jiménez Pelayo, Jesús. 1996. La descripción documental del fondo cartográfico antiguo: análisis de los aspectos conflictivos. En Revista Española de Documentación Científica. Vol. 19, no. 2, 131-149. <http://redc.revistas.csic.es/index.php/ redc/article/view/621/696> [Consulta: 23 noviembre 2020].

» Joint Steering Committee for Development of RDA, American Library Association, Library Association of Australia, British Library, Canadian Committee on Cataloguing, Library of Congress, Canadian Library Association, 
Deutsche Nationalbibliothek. 2015. RDA: Resource Description \& Access. Chicago, IL: American Library Association; Ottawa, ON: Canadian Library Association; London: CILIP Chartered Institute of Library and Information Professionals.

» Kandoian, Nancy. 1999. Cataloging early printed maps. En Andrew, Paige G. y Mary L. Larsgaard, ed. Maps and related cartographic materials: cataloging, classification and bibliographic control. Binghamton, N.Y.: Haworth Information Press. p. 229-264

»Karrow, Robert W. 1997. Manual for the cataloguing of antiquarian cartographic materials. 2nd draft. Chicago: Newbery Library.

»Library of Congress. Geography and Map Division. 1991. Map cataloguing manual. Washington, DC.: Cataloguing Distribution Service, Library of Congress.

»Machado Lorenzo, Nancy. 2009. Propuesta metodológica para el procesamiento de los materiales cartográficos manuscritos, su validación en los mapas de los siglos xviii y xix de la Biblioteca Nacional de Cuba José Martí. En Anales de Investigación. Año5, no. 5, 13-34. <http://eprints.rclis.org/25386/1/nancy.pdf> [Consulta: 23 noviembre 2020].

" Montoya Arango, Vladimir. 2007. El mapa de lo invisible. Silencios y gramática del poder en la cartografía. En Universitas humanística. No. 63, 156-179. <http:// www.scielo.org.co/pdf/unih/n63/n63a09.pdf> [Consulta: 23 noviembre 2020].

»Richter Scheuch, Marisol y Cynthia Valdivieso García. 2008. Iconografía. En Nagel Vega, Lina, ed. Manual de registro y documentación de bienes culturales. Santiago de Chile: Centro de Documentación de Bienes Patrimoniales, DIBAM. p. 96-99. <http://www.cdbp.patrimoniocultural.gob.cl/652/articles-26006_archivo_01.pdf> [Consulta: 23 noviembre 2020]. 
